\title{
The Roles of Shame and Guilt in Hypersexual Behavior
}

Randy Gilliland

Brigham Young University - Provo

Follow this and additional works at: https://scholarsarchive.byu.edu/etd

Part of the Psychology Commons

\section{BYU ScholarsArchive Citation}

Gilliland, Randy, "The Roles of Shame and Guilt in Hypersexual Behavior" (2010). Theses and Dissertations. 2568.

https://scholarsarchive.byu.edu/etd/2568

This Thesis is brought to you for free and open access by BYU ScholarsArchive. It has been accepted for inclusion in Theses and Dissertations by an authorized administrator of BYU ScholarsArchive. For more information, please contact scholarsarchive@byu.edu, ellen_amatangelo@byu.edu. 
The Roles of Shame and Guilt in Hypersexual Behavior

$$
\text { Randy Gilliland }
$$

\author{
A thesis submitted to the faculty of \\ Brigham Young University \\ in partial fulfillment of the requirements for the degree of \\ Master of Science
}

Mikle South, Ph.D., Chair

Bruce Carpenter, Ph.D.

Sam Hardy, Ph.D.

Department of Psychology

Brigham Young University

August 2010

Copyright (C) 2010 Randy Gilliland

All Rights Reserved 


\begin{abstract}
The Roles of Shame and Guilt in Hypersexual Behavior

Randy Gilliland

Department of Psychology

Master of Science

Studies among people struggling with hypersexual behavior commonly report that shame
\end{abstract} needs to be addressed when treating this population. These studies theoretically distinguish that it is shame and not guilt that exacerbates hypersexual behavior, yet no study to date has demonstrated this difference empirically. This observation led to the current investigation in which a sample $(N=177)$ of people seeking treatment for pornography use anonymously filled out measures of hypersexuality, shame-proneness, guilt-proneness, and motivation to change unwanted behavior. A hypothetical path model of the constructs was analyzed yielding significant positive relationships between shame-proneness and hypersexuality as well as guiltproneness and motivation to change. The data support previous findings that shame is active among people seeking treatment for hypersexual behavior. This study adds an additional element to the story by empirically demonstrating that shame and guilt have opposing relationships with hypersexuality and motivation for change.

Keywords: hypersexual behavior, hypersexual disorder, pornography use, shame, guilt 


\section{TABLE OF CONTENTS}

The Roles of Shame and Guilt in Hypersexual Behavior ....................................................... 1

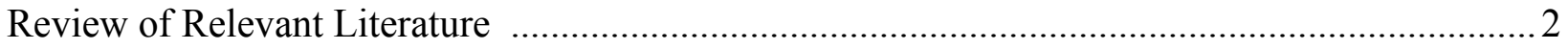

Review of Major Models of Excessive Sexual Behavior .......................................... 2

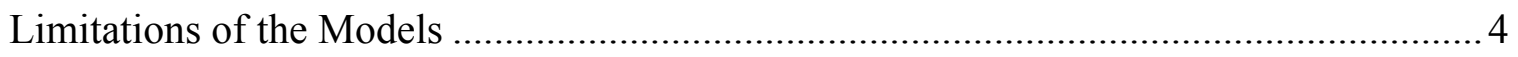

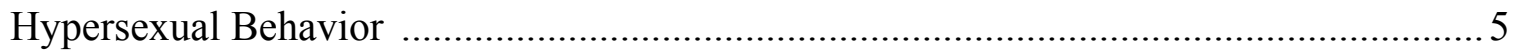

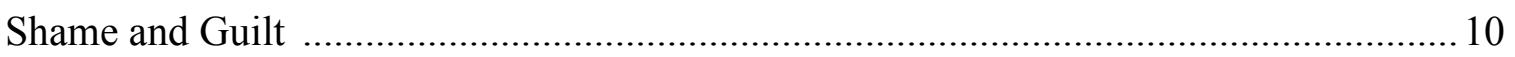

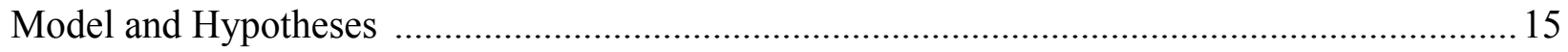

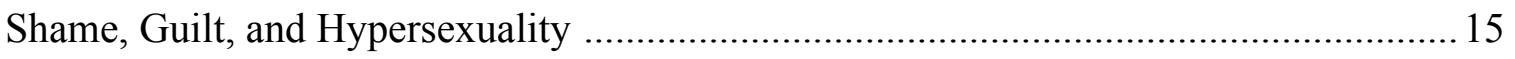

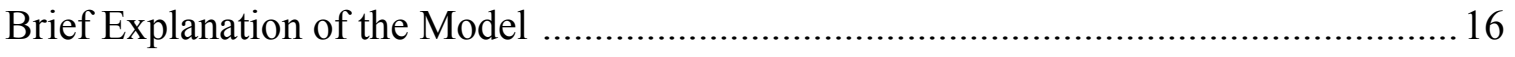

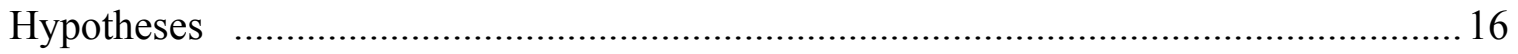

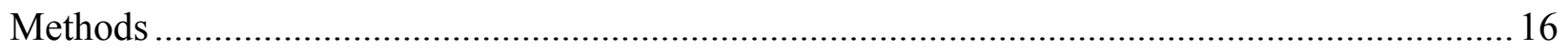

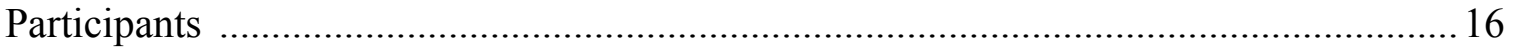

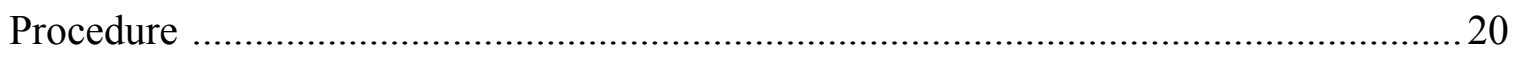

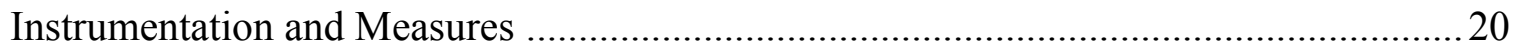

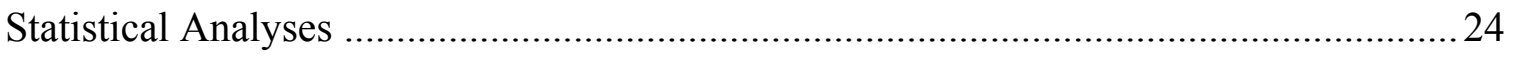

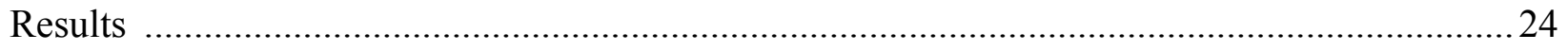

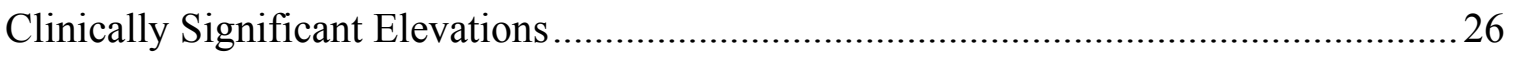

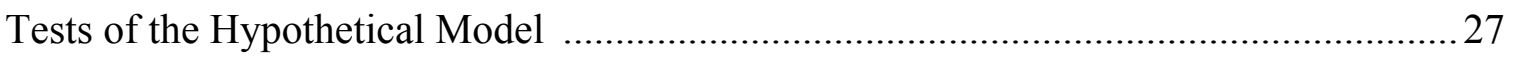

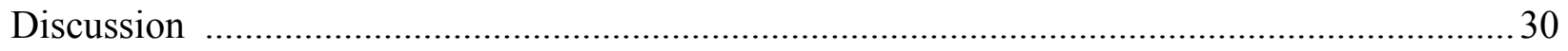

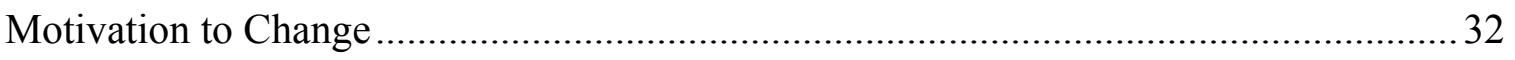

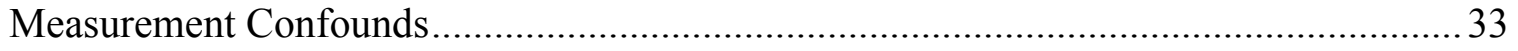


Limitations and Future Research

Conclusion

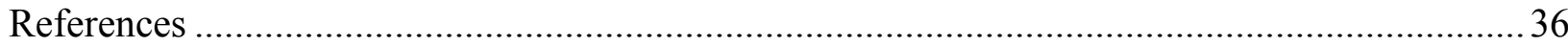

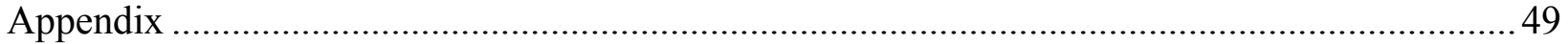

Sexual Concerns Outcome Questionnaire 


\section{The Roles of Shame and Guilt in Hypersexual Behavior}

In 1886, German psychiatrist Kraft-Ebbing described what he called "hypersensuality" as a condition in which sexual desire permeates "all thoughts and feelings, allowing of no other aims in life, tumultuously, and in rut-like fashion demanding gratification....and resolving itself into an impulsive, insatiable succession of sexual enjoyments" (Kraft-Ebbing, 1886, p. 70). This phenomenon of excessive sexual behavior has been spoken of through the decades under many different names, including: Don Juanism, nymphomania, erotomania, unrestrained sexual desire, and sexaholism.

Over the past few decades, attempts to both understand and improve treatment for excessive sexual behavior has led to the development of differing theoretical approaches to the causes and consequences of this phenomenon. Currently, the main theoretical models of excessive sexual behavior are: sexual addiction (Carnes, 1987; Earle \& Crow, 1990; Goodman, 1993, 2001; Lundy, 1994; Myers, 1995; Schwartz \& Brasted, 1985), sexual compulsivity (Travin, 1995), and sexual impulsivity (Barth \& Kinder, 1987). Despite differences in conceptualization of theory and measurement, each approach emphasizes the need to understand how hypersexual behavior continues despite significant, negative relational and personal consequences.

A growing area of research in this field is focused on habitual pornography use as associated with masturbation. Pornography use is one of the most commonly reported sexual behaviors in studies of excessive sexual behavior (Daneback, Ross, \& Månsson, 2006; Kafka \& Hennen, 1999; Reid, Carpenter, Gilliland, \& Karim, in press). Acknowledging this, Kafka 
(2010) included pornography dependence as a subtype of Hypersexual Disorder in his proposal for the inclusion of Hypersexual Disorder in the DSM-V (Kafka, 2010).

Another common topic discussed within the hypersexual literature is the need to confront shame when treating this population Adams and Robinson (2001) explain theoretically how the painful experience of shame, not guilt, is a key component in maintaining unwanted hypersexual behavior. Shame and guilt are negative self-evaluative emotions that arise after a mistake or failed attempt. A shame experience views the entire self as worthless or broken while a guilt experience views specific behavior as wrong. Although this and other studies (Reid, Harper, \& Anderson, 2008; Reid, Stein, \& Carpenter, under review) have demonstrated a relationship between shame and hypersexual behavior, the relationship between guilt and hypersexual behavior has not been analyzed empirically.

The focus of the present study is to understand how shame and guilt interact with excessive sexual behavior in a sample of adults who are currently receiving treatment for pornography use. Although several specific aspects of the current study have been analyzed in previous research, no study to date has assessed the interactions of shame, guilt, and excessive sexual behavior in this population. This paper begins with a review of several of the most prominent conceptualizations of excessive sexual behavior, followed by a review of the literature on the characteristics of the population from which this study will sample. Finally, a model is presented to describe the connection between shame, guilt, and excessive sexual behavior, followed by a description of the specific hypotheses. 


\section{Literature Review}

\section{Review of Major Models of Excessive Sexual Behavior}

Addiction. The sexual addiction model posits that excessive sexual behaviors arise from the same mechanisms that drive other addictive disorders (Carnes, 2001; Goodman, 1993). Sexual addiction has been defined operationally by four distinguishing features: (1) an uncontrollable, severe preoccupation with sex, (2) a sense of powerlessness, (3) a continuation of sexual behaviors regardless of aversive consequences, and (4) increasing sexual behavior as a tolerance is developed (Adams \& Robinson, 2001; Carnes, 2001; Goodman, 1993; Roller, 2004). A common criticism of classifying excessive sexual behavior as an addiction is the lack of research support demonstrating that the mechanisms of and treatment for excessive sexual behavior are the same as an addiction (Smith, 1994). The DSM-III-R listed Nonparaphilic Sexual Addiction under Sexual Disorders Not Otherwise Specified. However, due to the lack of empirical support for an addiction model for excessive sexual behavior (Smith, 1994) and the current climate surrounding sexual issues in psychiatry (Schmidt, 1992), this label was removed from the DSM-IV. Wood (2006) argues that the addiction model, although useful, runs the risk of portraying those viewed as addicted as "helpless in the face of an overwhelming stimulus and (are) thus disempowered" (p. 66).

Compulsion. Quadland (1985) has supported the view that people with excessive sexual behaviors use sex as a means of reducing anxiety, similar to acting on a compulsion. Quadland and others (Coleman, 1991; Travin, 1995) report that excessive sexual behaviors are used in these patients to reduce anxious feelings or to deal with unwanted affective experiences. The inability to regulate unpleasant affective states has been connected with excessive sexual 
behavior (Raymond, Coleman, \& Miner, 2003; Reid, Carpenter, Spackman, \& Willes, 2008;

Reid, Harper, \& Anderson, 2009), adding further support to the sexual compulsion model.

One concern with labeling excessive sexual behaviors as a compulsion is that sex stimulates the pleasure areas of the brain, while compulsions are not pleasure-based; typically, they are used as a means to reduce or avoid anxiety. Quadland (1985) however, argues that sex or sexual behaviors in excess desensitize people from the pleasure they experience and thus he believes it does constitute a compulsive tendency.

Impulse control. Barth and Kinder (1987) support a model classifying these behaviors as a manifestation of an impulse control disorder as described in the DSM, characterized by an inability to resist an impulsive act or behavior that might be harmful to self or others (APA, 1980). However, Bancroft and Vukadinovic (2004) note that the only explanation that Barth and Kinder give for the phenomenon of excessive sexual behavior is that it stems from a lack of selfcontrol, and that the model does not add any new knowledge about mechanisms of the behavior.

\section{Limitations of the Models}

The addiction, compulsion, and impulse control models offer explanations as to how and why these behavioral problems occur in this population. These explanations are beneficial and can serve as a means of understanding the behavior for treatment purposes, but each model lacks definitive empirical support. Also, each model assumes that each case of excessive sexual behavior is occurring under their theoretical orientation, excluding alternate explanations. Based on their clinical experience and research, Reid, Herper, and Anderson (2009) express concern with this practice, arguing that these "patients are not a homogenous group and that generalizations about this population should be made with caution" (p. 134). In order to provide a description of the behavior without the limitations of a model, excessive sexual behavior will 
be referred to as "hypersexuality", which is regarded as a more neutral, inclusive term, broad enough to encompass the other theoretical views without reference to how the behavior arises.

\section{Hypersexual Behavior}

The term "hypersexual behavior" (Stein, Black, Shapira, Spitzer, 2001), has been used in order to describe excessive sexual behavior without reference to any particular theory. Much of the medical literature uses the term to describe abnormal sexual behavior due to a neurological condition, a side effect of medication, or illicit drug use (Finlayson, Sealy, \& Martin, 2001; Roane, Yu, Feinberg, \& Rogers, 2002; Washton, \& Boundy, 2000). This use overlooks the phenomenon in other situations that may be more enduring and that may be amenable to psychosocial as well as medical intervention. There is a current need for research among hypersexual populations as the American Psychiatric Association is considering including Hypersexual Disorder as a diagnostic category under Sexual and Gender Identity Disorders in the DSM-5. Table 1 presents the proposed diagnostic criteria for Hypersexual Disorder in the DSM-5 (Kafka, 2010). 
Table 1

Proposed Diagnostic Criteria for Hypersexual Disorder

A. Over a period of at least six months, recurrent and intense sexual fantasies, sexual urges, and sexual behavior in association with four or more of the following five criteria:

(1) Excessive time is consumed by sexual fantasies and urges, and by planning for and engaging in sexual behavior.

(2) Repetitively engaging in these sexual fantasies, urges, and behavior in response to dysphoric mood states (e.g., anxiety, depression, boredom, irritability).

(3) Repetitively engaging in sexual fantasies, urges or behaviors in response to stressful life events.

(4) Repetitive but unsuccessful efforts to control or significantly reduce these sexual fantasies, urges, and behavior.

(5) Repetitively engaging in sexual behavior while disregarding the risk for physical or emotional harm to self or others.

B. There is clinically significant personal distress or impairment in social, occupational or other important areas of functioning associated with the frequency and intensity of these sexual fantasies, urges, and behavior.

C. These sexual fantasies, urges, and behavior are not due to direct physiological effects of exogenous substances (e.g., drugs of abuse or medications) or to Manic Episodes.

D. The person is at least 18 years of age.

Specify if:

Masturbation

Pornography

Sexual Behavior With Consenting Adults

Cybersex

Telephone Sex

Strip Clubs

Other:

Note. Proposed diagnostic criteria for diagnosing Hypersexual Disorder. Taken from www.dsm5.org 
Associations of hypersexual behavior. Kafka (2010) conceptualizes hypersexuality as a "nonparaphilic sexual desire disorder with an impulsivity component" (p. 377). Hypersexual individuals seek to satisfy their intense sexual drives through self-stimulation, pornography use, exhibitionism, and other risky sexual behaviors (Black, Kehrberg, Flumerfelt, \& Schlosser, 1997; Reid et. al, 2008; Travin, 1995). Studying ways to help individuals reduce hypersexual behaviors is important because the possible risks to self and others are great, including: unwanted pregnancies, sexually transmitted diseases, guilt and/or shame from sexual activities, loss of employment, and family and other relationship problems (Roller, 2004).

Influence of the Internet. The recent increase in research in the field of hypersexual behavior has been attributed to an increase in patients requiring treatment for these behaviors (Reid, Carpenter, Spackman, \& Willes, 2008). One of the main explanations for this increase is the access that the Internet gives to sexual materials, including easy and anonymous access to pornographic materials, sexually-focused chat rooms, and even sexual partners (Cooper, Putnam, Planchon, \& Boies, 1999; McFarlane, Bull, \& Rietmeijer, 2000). It is possible that the apparent rise in hypersexual behavior, especially pornography use (Cooper, Delmonico, \& Burg, 2000), arises from the unprecedented availability and lure of sexual materials on the Internet that Cooper (1998) has called the "Triple-A Engine" effect of accessibility, affordability, and anonymity. Because these materials and forums can be accessed at anytime, for free or relatively inexpensively, and can be used without revealing any identity, individuals who may have previously been deterred by such obstacles may now become more easily attracted and have difficulty avoiding hypersexual behavior.

The problem becomes even more compounded as life becomes more and more dependent on the Internet, and as technological advances make the Internet more accessible. School, work, 
and other pursuits require access to the Internet. New technology has made it so the Internet can be used on telephones and other hand-held devices. These advances have obvious benefits, but have also allowed further access to sexual materials, making it harder for those with hypersexual tendencies to avoid such material without close supervision or blocking software.

Pornography and hypersexual behavior. A proposed subtype of Hypersexual Disorder involves excessive consumption of pornography (Kafka, 2010), which has been associated with negative effects on users and their committed relationships (Bridges, Bergner, \& HessonMcInnis, 2003; Oddone-Paolucci, Genuis, \& Violato, 2000). Kafka (2010) conceptualizes pornography as including, but not limited to "visual as well as explicitly sexually arousing text materials, including magazines, internet images, and videos" (p. 387).

The Internet has become a popular venue for people to access sexual content; the only requirement for access is basic computer knowledge and an Internet connection. Of all the topics that can be searched on the Internet, it has been found that searches on the subject of "sex" are the most frequent (Cooper, 2004). The growing popularity of internet pornography worldwide leads one to wonder what effects, if any, does pornography use have on users and their relationships?

Characteristics of pornography users. Similar to other potentially habit-forming activities, there are casual users of pornography as well as others that become consumed with the practice, spending most of their free time viewing sexual material. Of the 9,177 respondents to a survey study conducted by Cooper, Putnam, Planchon, and Boies (1999), 43\% spent less than an hour per week seeking sexual material online while $8 \%$ spent 11 hours or more per week seeking out such material. In a follow up study, Cooper, Delmonico, and Burg (2000) re-analyzed the data collected in the previous study in order to better understand the online behavior of these two 
groups. Based on their responses to the Sexual Compulsivity Scale (Kalichman, Johnson, Adair, Rompa, Multhauf, \& Kelly, 1994) the sample was divided into four groups: nonsexually compulsive, moderately sexually compulsive, sexually compulsive, and cybersexually compulsive (met criterion for sexual compulsivity as well as reported spending an average of 15 or more hours per week seeking sexual material online). Main findings of the study include:

- Students are more likely to be members of the cybersex compulsive group compared to professionals.

- Regardless of the level of sexual compulsivity, $6 \%$ of employees use their work computer for sexual materials.

- Women prefer chat rooms to all other forms of online sexual material.

- Members of the sexually compulsive and cybersexually compulsive groups were predominantly married, heterosexual males.

There have been no longitudinal studies to date that assess the characteristics that lead from casual pornography use to hypersexual behavior. The only way to bridge that gap currently is to make inferences between studies of users of pornography and studies of people demonstrating hypersexual behavior, since pornography use is one of the main problematic sexual behaviors in studies of hypersexuals. Studies on psychopathology within hypersexual samples have found connections between hypersexuality and depression (Kafka \& Hennen, 2002), mood and anxiety disorders (Raymond, Coleman, \& Miner, 2003), stress proneness, emotional instability, and alexithymia (Reid, Carpenter, Spackman, \& Willes, 2008). Reid (2010) found that, compared to a control group, clients receiving therapy for hypersexual behavior had significantly lower levels of positive emotion and higher levels of negative emotion as assessed by the Differential Emotions Scale (DES-IV; Boyle, 1984). After further analysis, 
the emotion most predictive of hypersexual behavior was Self-Hostility, which can be characterized as harsh self-criticism. Another study found that attacking the self is a coping mechanism used by hypersexual patients to defend against the painful effects caused by shame (Reid, Harper, \& Anderson, 2009). In light of connections between hypersexuality and negative emotional and mood states, it has been hypothesized that people use hypersexual behaviors as a way to alleviate negative affect and negative mood states (Adams \& Robinson, 2001).

\section{Shame and Guilt}

Two negative emotional states that have been discussed in connection with hypersexual behavior are shame and guilt. The definitions of shame and guilt are the source of considerable confusion in the literature. The origin of the word shame is unknown, but it is assumed by scholars that an early form of the word meant "to cover" and is synonymous with the words dishonor, ridicule, humiliation, mortification, chagrin, and embarrassment (Lewis, 1971, pp. 6374). Guilt, on the other hand, is assumed to stem from the Teutonic root Schuld, which means debt (Lewis, 1971, p 76).

Some researchers use the terms interchangeably (Potter-Efron, 1989), while others view them as distinct constructs (Lewis, 1971; Tangney \& Dearing, 2002). Following the description introduced by Lewis (1971), this paper characterizes both shame and guilt as self-conscious emotions involved in negative self-evaluation. The difference between the two is the target of the negative evaluation. When a person experiences shame, the negative evaluation is directed toward the self as a whole. When guilt is experienced, the negative evaluation is directed at the behavior that produced those feelings. Guilt says "my behavior is bad" while shame says "I am a bad person". 
In empirical studies, guilt has been connected to constructive actions like repairing relationships with those affected by a specific behavior, while shame has been linked with emotional avoidance and aggression (Tangney, 1991; Tangney, Wagner, Fletcher, \& Gramzow, 1992). These putative differences in attribution between guilt and shame have fueled hypotheses that shame is maladaptive and more related to psychopathology than guilt. When controlling for shame, the correlations between guilt and depression become significantly smaller or are eliminated altogether (Harder, Cutler, \& Rokart, 1992; Stuewig \& McCloskey, 2005; Tangney, Wagner, \& Gramzow, 1992). In two separate studies, young adults were asked to describe a personal guilt experience and a personal shame experience, and then rate how they felt during the experiences using multiple measures which assessed the emotional magnitude of the situations (Tangney, 1991; Tangney, Miller, Flicker, \& Barlow, 1996). In both studies, the participants rated the shame experiences as significantly more painful and intense than the guilt experiences. Many would argue that the notion that shame is bad while guilt is good only tells half of the story. Simplifying guilt to a constructive, adaptive emotion leaves out its ruminative, maladaptive functions that are spoken of in the literature (Ferguson \& Crowley, 1997). One of the diagnostic criteria used for a major depressive episode involves "feelings of worthlessness or excessive or inappropriate guilt ... nearly every day" (American Psychiatric Association [APA], 2000, p. 356). Guilt may become maladaptive in situations where restitution or confession is not possible, such as after the death of a close friend, spouse, or family member (Bybee \& Quiles, 1998; Lindsay-Hartz, de Rivera, \& Mascolo, 1995). Quiles and Bybee (1997) found that continual feelings of guilt, not tied to any specific event, have a stronger relationship with overall psychopathology than acute feelings of guilt that stem from specific situations. In response to the theory that maladaptive guilt is just guilt fused with shame (Tangney, Burggraf, \& Wagner, 
1995), Quiles and Bybee (1997) found that this ongoing feeling of guilt regardless of the situation, which they refer to as "chronic guilt", is a separate construct from shame. The chronic guilt items from their scale loaded on the same factor as shame items from other measures, but the relationship between chronic guilt and psychopathology remained the same even after the shame items were taken out of the picture. This view of guilt as a primarily constructive emotion bypasses its potentially destructive consequences.

Although not empirically tested, possible benefits of shame have been theorized. As characterized by Lewis (1971), the feeling of shame can have can have multiple sources, one of them being "a situation which offends one's sense of modesty or decency" (p. 64). In this context, the threat of shame could be a possible motivation to avoid potentially shameful behavior. This function of shame, spoken of by Izard (1977), allows an individual to develop the skills and competencies needed to function within a group. In other words, there are benefits of shame for the individual and society inasmuch as the threat of shame limits inappropriate behavior.

With the limitations of using a narrow characterization of shame and guilt in mind, the definitions used by Tangney and Dearing (2002) will be used for this paper. These limitations will be applied to the findings and will be analyzed further in the Discussion section.

Factors leading to shame or guilt. Shame is viewed as a moral emotion where a person focuses on himself as wrong whereas guilt is viewed as a moral emotion where a person focuses on his behavior as wrong (Lewis, 1971; Tangney \& Dearing, 2002). It is argued that shame is brought on by public embarrassment, while guilt does not require the presence of others (Mingyi \& Jianli, 2002). Tangney (1991) conducted a study where undergraduates were asked to describe three personal shame-inducing situations and three personal guilt-inducing situations. 
Those experiencing shame were more likely to be concerned with how others viewed them. Those experiencing guilt were more likely to be concerned with their effect on others. The situation itself did not influence whether shame or guilt was experienced (Tangney, 1991). Combining these two arguments, Herman (2007) concluded that "Shame is an acutely selfconscious state in which the self is 'split,' imagining the self in the eyes of the other; by contrast, in guilt the self is unified" (p. 8). So inherent in shame is a feeling of unworthiness or judgment of the self by another, whether real or imagined. As characterized by Lewis (1971) and Tangney and Dearing (2002), focusing negatively on the self leads to shame while focusing negatively on behavior, sparing the self, leads to guilt. Under this characterization, the path from a guilt or shame-inducing situation to either shame or guilt depends upon the individual reaction of the person.

Shame in a hypersexual population. Relationships between shame and signs of psychopathology have been shown for anxiety, depression, obsessive-compulsive disorders, and decreased self-efficacy (Baldwin, Baldwin, \& Ewald, 2006); violence (Brown, 2004); aggression (Covert, 2004); and substance-abuse disorders, post-traumatic stress disorders, and low self-esteem (Harder, 1995; Lewis, 1987; Tangney \& Dearing, 2002; Yelsma, Brown, \& Elison, 2002). Anxiety, depression, obsessive-compulsive disorders, substance-abuse disorders, and low self-esteem have also been seen in hypersexual populations, but only two empirical studies to date have demonstrated a relationship between shame and hypersexual behavior (Reid, Harper, \& Anderson, 2008; Reid, Stein \& Carpenter, under review). Beyond that, the literature connecting the two is limited to suggestions by clinicians that, in order to break the compulsive cycle of these behaviors, shame needs to be confronted and resolved (Adams \& Robinson, 2001; Hastings, 1998; Wilson, 2000). Clearly, more research is needed to identify more specific 
connections between shame and hypersexual behavior. No study to date has tried to examine how shame and guilt interact differently in a hypersexual sample. The purpose of this study is to assess if shame and guilt have differing relationships with hypersexual behavior among people receiving treatment for pornography use.

Shame leads to increased hypersexual behavior. Studies have shown that people that are involved in hypersexual behaviors use those behaviors to deal with personal or interpersonal distress (Reid, Carpenter, Spackman, Willes, 2008). Tangney (2002) found that shame has a strong positive relationship with externalization (blaming others or circumstances for your own behavior) and suggested that shame experiences are so painful that shamed individuals decide to take the blame off themselves and place it elsewhere. A 1994 study found that compared to a non-addicted sample, addicts were significantly higher in proneness to shame and externalization (O’Connor, Berry, Inaba, Weiss, 1994). These addicts may be self-medicating to treat the psychological pain of shame and their externalization may be keeping them ignorant of the magnitude of their addiction. It is proposed that hypersexual behavior is used as a coping mechanism to deal with the painful experience of shame, and that shame will have a positive relationship with measures of hypersexuality but a negative relationship with change associated with unwanted behavior.

Guilt leads to corrective behavior. Those experiencing guilt tend to focus on their behavior and its effect on others (Tangney, 2002). Tangney (1991) found that guilt experiences tend to be more empathic and other-oriented. For this study, it is proposed that: guilt scores among those receiving treatment for hypersexual behavior will have a negative relationship with scores on the Hypersexual Behavioral Inventory (HBI) compared to shame because the experience of guilt tends to motivate a person to change behavior that is viewed as wrong. It is 
also proposed that guilt will have a positive predictive relationship with motivation to change unwanted behavior and specific behaviors associated with limiting pornography use.

\section{Model and Hypotheses}

\section{Shame, Guilt, and Hypersexuality}

My participant sample is comprised of clients of an online treatment program for pornography use, as well as students and members of the community surrounding an intensely religious private university who are receiving therapy related to their use of pornography. The majority of the participants describe themselves as religious, which may be one explanation for their desire to curb their pornography use. Thus, the everyday religious and cultural context likely exacerbates the shame and guilt that the participants are experiencing. Below is Figure 1, a hypothesized model of the relationships between shame, guilt, and hypersexual behavior.

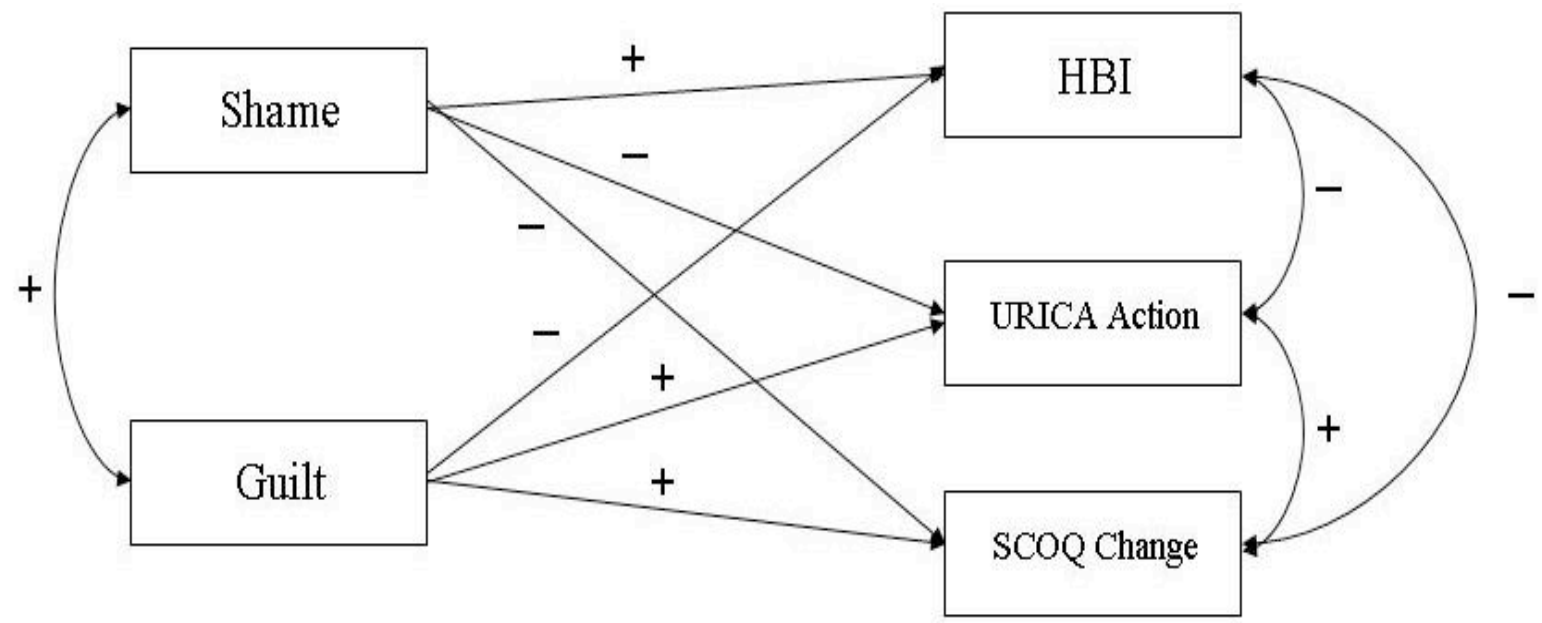

Figure 1. Hypothesized structural equation model of the relationship between shame and guilt and hypersexual behavior (assessed by the HBI) and change associated with pornography use (assessed by the URICA Action and the SCOQ Change). The Hypersexual Behavioral Index (HBI) is from Reid and Garos (2007); the Test of Self-Conscious Affect (TOSCA) Shame and Guilt are from Tangney and Dearing (2002); the University of Rhode Island Change Assessment (URICA) Action is from McConaughy et al. (1983); the Sexual Concerns Outcome Questionnaire ( $\mathrm{SCOQ}$ ) Change is from the Brigham Young University Career and Counseling Center, with additional questions written by the authors for this study (see appendix). 


\section{Brief Explanation of the Model}

The model hypothesizes that hypersexual behavior (assessed by the HBI) is positively associated with shame and negatively associated with guilt while corrective behavior (assessed by the URICA Action and the SCOQ Change) is positively associated with guilt and negatively associated with shame. It is also hypothesized in the model that the TOSCA Shame and TOSCA Guilt measures will have a positive relationship, the HBI will have a negative relationship with the URICA Action and SCOQ Change, and the URICA Action and SCOQ Change will have a positive relationship.

\section{Hypotheses}

H1: Shame will have a positive relationship and guilt will have a negative relationship with the Hypersexual Behavioral Inventory (HBI) among participants receiving therapy for hypersexual behavior.

H2: Guilt will have a positive relationship with corrective behaviors as assessed by the Action subscale of the URICA and the corrective behavior questions in the Sexual Concerns Outcome Questionnaire while shame will be negatively related to the same constructs.

\section{Methods}

\section{Participants}

The sample was composed of 177 people ages $18-73(M=34.46, S D=12.79[10$ nonresponders to age]); who were predominantly Caucasian males receiving either therapy (5.6\% at a university counseling and career center and $3.4 \%$ at an outpatient mental health clinic) or an online treatment ( $91 \%$ of the sample) for hypersexual behaviors. Because this was a crosssectional study of people in treatment, participants varied in the lengths that they had been in treatment; some had just begun while some had been in treatment for several years. The 
participants were mostly educated and had some sort of religious affiliation. All other demographic information is reported in Table 2. No location information was collected. 
Table 2

Participant Demographics

\begin{tabular}{|c|c|c|c|c|}
\hline Category & Subcategory & $n$ & $\%$ of Sample & \# Missing in Category \\
\hline \multirow[t]{2}{*}{ Gender } & Male & 170 & 98.8 & 5 \\
\hline & Female & 2 & 1.2 & \\
\hline \multirow[t]{5}{*}{ Race } & African-American & 7 & 4 & 3 \\
\hline & Hispanic & 6 & 3.4 & \\
\hline & White & 150 & 84.7 & \\
\hline & Asian-Pacific Islander & 6 & 3.4 & \\
\hline & Other & 5 & 2.8 & \\
\hline \multirow[t]{3}{*}{ Sexual Orientation } & Heterosexual & 161 & 91 & 4 \\
\hline & Bisexual & 3 & 1.7 & \\
\hline & Gay & 9 & 5.1 & \\
\hline \multirow[t]{7}{*}{ Income } & Less than $\$ 10,000$ & 33 & 18.6 & 4 \\
\hline & $\$ 10,000-\$ 19,999$ & 19 & 10.7 & \\
\hline & $\$ 20,000-\$ 39,999$ & 37 & 20.9 & \\
\hline & $\$ 40,000-\$ 59,999$ & 23 & 13 & \\
\hline & $\$ 60,000-\$ 79,999$ & 22 & 12.4 & \\
\hline & $\$ 80,000-\$ 100,000$ & 19 & 10.7 & \\
\hline & more than $\$ 100,000$ & 20 & 11.3 & \\
\hline \multirow[t]{3}{*}{ Marital Status } & Single, never married & 83 & 46.9 & 3 \\
\hline & Married & 75 & 42.4 & \\
\hline & & & & (table continues) \\
\hline
\end{tabular}




\begin{tabular}{|c|c|c|c|c|}
\hline Category & Subcategory & $n$ & $\%$ of Sample & \# Missing in Category \\
\hline & Separated & 6 & 3.4 & \\
\hline & Divorced & 8 & 4.5 & \\
\hline & Widowed & 2 & 1.1 & \\
\hline \multirow[t]{3}{*}{ Location } & University & 10 & 5.6 & \\
\hline & Clinic & 6 & 3.4 & \\
\hline & Online & 161 & 91 & \\
\hline \multirow[t]{7}{*}{ Education } & Less than high school & 4 & 2.3 & 3 \\
\hline & High school/GED & 13 & 7.3 & \\
\hline & Some college & 46 & 26 & \\
\hline & 2-year college degree & 19 & 10.7 & \\
\hline & 4-year college degree & 54 & 30.5 & \\
\hline & Master's degree & 24 & 13.6 & \\
\hline & $\begin{array}{l}\text { Doctoral or professional } \\
\text { degree }\end{array}$ & 14 & 7.9 & \\
\hline \multirow[t]{3}{*}{ Religion } & Protestant & 15 & 8.5 & 2 \\
\hline & Catholic & 24 & 13.6 & \\
\hline & Evangelical Christian & 25 & 14.1 & \\
\hline
\end{tabular}

Note. Demographic characteristics of the sample. 


\section{Procedure}

The hypersexual sample was a convenience sample chosen because they were already in therapy or an online treatment for pornography use. The online treatment (www.candeocan.com) consists of ten guided lessons and other resources to help their clients curb their pornography use and compulsive masturbation. Testing only occurred after consent had been obtained at the beginning of the online survey. Participants received no incentive for participation. The participants in therapy were recruited by their therapists at a university counseling center and a local private practice and, if interested, were given a card with the study web address (www.psychologysurvey.net) as well as a log-in password. Participants that were using the online treatment were emailed a link to the survey and a log-in password and were encouraged to participate. Once logged on, participants had access to a Qualtrics ${ }^{\mathrm{TM}}$ survey that included a consent form, a demographics measure, the Test of Self Conscious Affect-Short Version (TOSCA-S), the Hypersexual Behavioral Inventory (HBI), the Sexual Concerns Outcome Questionnaire (SCOQ), and the University of Rhode Island Change Assessment. (URICA). The online survey was completely anonymous and no identifying information other than the demographics questions was obtained.

\section{Instrumentation and Measures}

Demographics. Demographic information, including age, gender, relationship status, living situation, work status, religious affiliation, education, income, sexual orientation, and ethnicity was collected.

Hypersexual Behavioral Index (HBI). The HBI (Reid \& Garos, 2007) was used to assess each participant's level of hypersexuality. The HBI is a 19-item self-report measure with three subcategories which asses the degree to which respondents feel they are unable to control 
their sexual thoughts, feelings and behavior ("I engage in sexual activities that I know I will later regret"); the extent to which they use sexual behavior as a means of coping with emotional discomfort ("Doing something sexual helps me cope with stress"); and the extent to which they experience negative consequences due to their sexual activities ("My sexual thoughts and fantasies distract me from accomplishing important tasks"). Participants respond to each question on a 5-point Likert scale that ranges from 1 (never) to 5 (very often). The overall reliability of the scale been shown to be high $(\alpha=.95)$, along with the Control $(\alpha=.91)$, Coping $(\alpha=.91)$, and Consequences $(\alpha=.89)$ subscales. The HBI has demonstrated concurrent validity with the Compulsive Sexual Behavior Inventory $(r=.92, p<.01)$, the Sexual Compulsivity Scale $(r=.82, p<.01)$, and the Sexual Addiction Screening Test $(r=.92, p<.01)$. A total HBI score of 53 has been designated as the cut-off to signify problems with hypersexual behavior with higher scores indicating greater hypersexuality (Reid \& Garos, 2007). The HBI scores were used to test hypotheses 1 and 2. It was expected that scores on the HBI would have a negative relationship with guilt proneness scores and a positive relationship with shame proneness scores.

Test of Self Conscious Affect -Short Version (TOSCA-S). The TOSCA-3 (Tangney \& Dearing, 2002) is a scenario-based measure of guilt and shame proneness. The TOSCA-3 contains 16 brief scenarios, 11 of which contain negative situations and 5 contain positive situations. Each situation is followed by four separate responses, each with a five-point scale that ranges from 1 (not likely) to 5 (very likely), where participants rate the likelihood that they will react according to that response. The scenarios and responses were taken from written shame, guilt, and pride experiences of adults and represent daily situations that can induce shame and/or guilt. The measure provides six different scores for each participant: proneness to shame, proneness to guilt, externalization of blame, detachment-unconcern, pride in self (alpha pride), 
pride in behavior (beta pride). Previous research has provided support for the reliability of the TOSCA-3's shame and guilt scales. Tests of internal consistency have shown a Cronbach's alpha score of .74 for the shame scale and .61 for the guilt scale (Tangney, Wagner, Barlow, Marschall, \& Gramzow, 1996). Higher test-retest reliabilities for the shame scale (.85) and guilt scale (.74) have also been reported over a three to five week period (Tangney, Wagner, Fletcher, \& Gramzow, 1992). The present study used an 11-scenario shortened and modified version of the TOSCA-3 (TOSCA-S) that omits the pride scenarios from the measure. The proneness to guilt and proneness to shame scores were used to test the two hypotheses. It was hypothesized that scores on the proneness to shame scale would have a positive relationship with the HBI and a negative relationship with the SCOQ Change and the URICA Action. It was also expected that scores on the proneness to guilt scale will have a negative relationship with the HBI and a positive relationship with SCOQ Change and the URICA Action.

One advantage of the TOSCA-S is that it allows shame and guilt to vary independently of each other, meaning that a participant can rate an experience as provoking both shame and guilt. Because shame and guilt are rated independently, the TOSCA-S captures the shared variance between the two. This will allow the researchers to assess how shame and guilt interact with the other constructs.

Some have expressed concerns about what the TOSCA is actually measuring. Luyten, Fontaine, and Corveleyn (2002) tested the theory that the TOSCA only measures adaptive forms of guilt and maladaptive forms of shame. After examining the guilt items, they conclude that the TOSCA Guilt scale does include maladaptive forms of guilt (remorse, regret, and rumination) but those items are underrepresented when compared to the items that address reparative behavior. The TOSCA Shame scale however, does not include potentially adaptive forms of 
shame. These concerns possibly have effects on the interpretation of the results and will be further analyzed in the Discussion section.

Sexual Concerns Outcome Questionnaire (SCOQ). The SCOQ is a measure developed by the clinicians at the Brigham Young University Career and Counseling Center to assess the effectiveness of their sexual concerns therapy groups. The SCOQ was originally designed to be administered online to former members of these groups to compare their pre- and post-therapy frequencies of masturbation and pornography use. Since this study only focused on current behaviors, SCOQ questions that referred to pre-therapy behavior were taken out. I added an additional set of 9 questions that address specific behavioral changes referring to the participants' efforts to limit their pornography use. These questions were developed by interviewing various therapists that work with people in treatment regarding their pornography use. The scores from these 9 questions were combined to create the SCOQ Change variable used in hypothesis 2 .

University of Rhode Island Change Assessment (URICA). Also known as the Stages of Change Scale (SCS), the URICA (McConnaughy, Prochaska, \& Velicier, 1983) is a 32-item questionnaire based on the Stages of Change model (Prochaska \& DiClemente, 1982). The majority of the questions on the URICA refer to a generic "problem", which the developers leave open for the clinician or client to define. The "problem" in this study was defined as the participant's pornography use.

The questionnaire consists of four subscales: Pre-Contemplation (not recognizing a problem), Contemplation (recognizing a problem but not acting on it), Action (actively trying to fix a problem), and Maintenance (an attempt to maintain changes already made). The scales have demonstrated the following internal consistency: Pre-Contemplation, .88; Contemplation, 
.88; Action, .89; and Maintenance, .88 (McConnaughy et al., 1983). The Action subscale was used to test hypothesis 2 .

\section{Statistical Analyses}

The data was exported from Qualtrics ${ }^{\mathrm{TM}}$ into an SPSS Statistics Version 17 database. Composite variables for the HBI, TOSCA Shame, TOSCA Guilt, URICA Action, and SCOQ Change scales were calculated by summing up the scores. Descriptive statistics of the sample, correlations, and reliabilities for each scale were completed using SPSS. The data was then formatted to be uploaded into the Mplus program to test both hypotheses contained in the hypothetical model (Figure 1).

Structural equation modeling (SEM). SEM was used to assess how well the proposed model fits the data. SEM is a statistical technique used to test the associations hypothesized in a model by using the linear regression equation to assess how well the proposed model represents the effects between one or more predictor variables and one or more dependent variables (Bentler, 1980). In an SEM diagram, squares represent observed variables, lines show a regression path between the two variables, and a variable with an arrow pointing to it is a dependent variable (Ullman, 1996). This study will be using path analysis, which is a form of SEM that provides indices of model fit, simultaneously estimates model paths, and can account for missing data.

\section{Results}

Participants were recruited over the course of four months. The means, standard deviations, ranges, and alpha scores for all variables are displayed in Table 3. None of the measures had complete data from every participant; missing data was due to participant omission. Only measures with complete data were included in the analyses. 
Table 3

Correlations, Descriptive Statistics, and Reliability Coefficients for Model Variables

\begin{tabular}{lcccccccccccc}
\hline Variables & 1. & 2. & 3. & 4. & 5. & $N$ & $M$ & SD & Range $f^{2 \dagger}$ Alpha \\
\hline 1. HBI & 1.0 & & & & & 149 & 70.11 & 13.74 & $23-95$ & .11 & .93 \\
2. TOSCA Shame & $.27 * *$ & 1.0 & & & & 147 & 31.12 & 7.53 & $13-47$ & N/A & .77 \\
3. TOSCA Guilt & -.054 & $.345^{* * *}$ & 1.0 & & & 148 & 45.32 & 5.19 & $28-55$ & N/A & .68 \\
4. URICA Action & .027 & -.053 & $.282^{* * *}$ & 1.0 & & 159 & 33.82 & 3.55 & $24-40$ & .12 & .77 \\
5. SCOQ Change & $-.251^{* *}$ & -.152 & .105 & $.365^{* * *}$ & 1.0 & 159 & 23.84 & 4.12 & $10-35$ & .05 & .62 \\
\hline
\end{tabular}

Note. The Hypersexual Behavioral Index (HBI) is from Reid and Garos (2007); the Test of Self-Conscious Affect (TOSCA) Shame and Guilt are from Tangney and Dearing (2002); the University of Rhode Island Change Assessment (URICA) Action is from McConaughy et al. (1983); the Sexual Concerns Outcome Questionnaire (SCOQ) Change is an intake questionnaire from the Brigham Young University Career and Counseling Center, with additional questions written by the authors for this study (see appendix). All values represent raw, nonstandardized scores.

${ }^{\dagger}$ Cohen's $f^{2}$ is a measure of effect size of dependent variables when using multiple regression.

$* p<.05 ; * * p<.01 ; * * * p<.001$ 
After calculating the descriptive statistics, the SPSS Statistics Explore function was used to examine each measure for individual outliers. Every measure except for the TOSCA Shame had extreme outliers, the most being four extreme outliers on the SCOQ Change. None of the participants were consistent outliers across measures. Comparing the $5 \%$ trimmed mean to the original mean for each measure revealed no significant influences from the extreme outliers; thus, the analyses presented below utilize all complete participant data.

\section{Clinically Significant Elevations}

The participants have spent an average of 15.94 years of their lives actively participating in activities related to pornography $(S D=10.97)$ and 1.25 years in treatment for pornography use $(S D=1.98)$. The sample mean for the HBI was $70.11(S D=13.74)$, with $90.6 \%$ of the sample above the established cut-off of 53. To provide some context for the elevated mean HBI score, the male clinical sample reported by Reid and Garos (2007) had a mean HBI score of $66.3(S D=$ 13.8) while the combined college sample had a mean score of $29.9(S D=11.9)$. Although these data alone do not substantiate classifying the entire sample as hypersexual, they illustrate that pornography use has become an ongoing problem and a significant source of distress among this sample.

The sample had interesting comparisons with the other measures used. McConnaughy, Prochaska, and Velicer (1983) used the URICA among a sample of 155 people receiving outpatient therapy in several locations. They reported 16.64 as the mean URICA Action score $(S D=5.14)$ while our sample had a mean score of $33.82(S D=3.55)$. Our sample is much more homogenous, both demographically and the problem they are addressing in treatment than the sample used in McConnaughy, Prochaska, and Velicer (1983), which might be an explanation of 
the variance in these scores. The SCOQ Change scale was developed for this project and had no previous data to compare to.

\section{Tests of the Hypothetical Model}

The two hypotheses contained within the model were analyzed using path analysis. Path analysis, in essence, is a type of multiple regression which aims at testing the hypothetical direction of a relationship between variables and follows the same assumptions as multiple regression. All dependent variables in the model are continuous, so a linear regression model will be used. The current study exceeded the sample size recommendations by Kline (2005), which are 5 subjects for every model parameter. The hypothetical model was tested using the statistical software package Mplus 5 (Muthén \& Muthén, 2007) utilizing full inform maximum likelihood estimation (FIML), which includes all cases with complete data on at least one variable into the analysis. The results from the path analysis are reported in Figure 2 and Table 4.

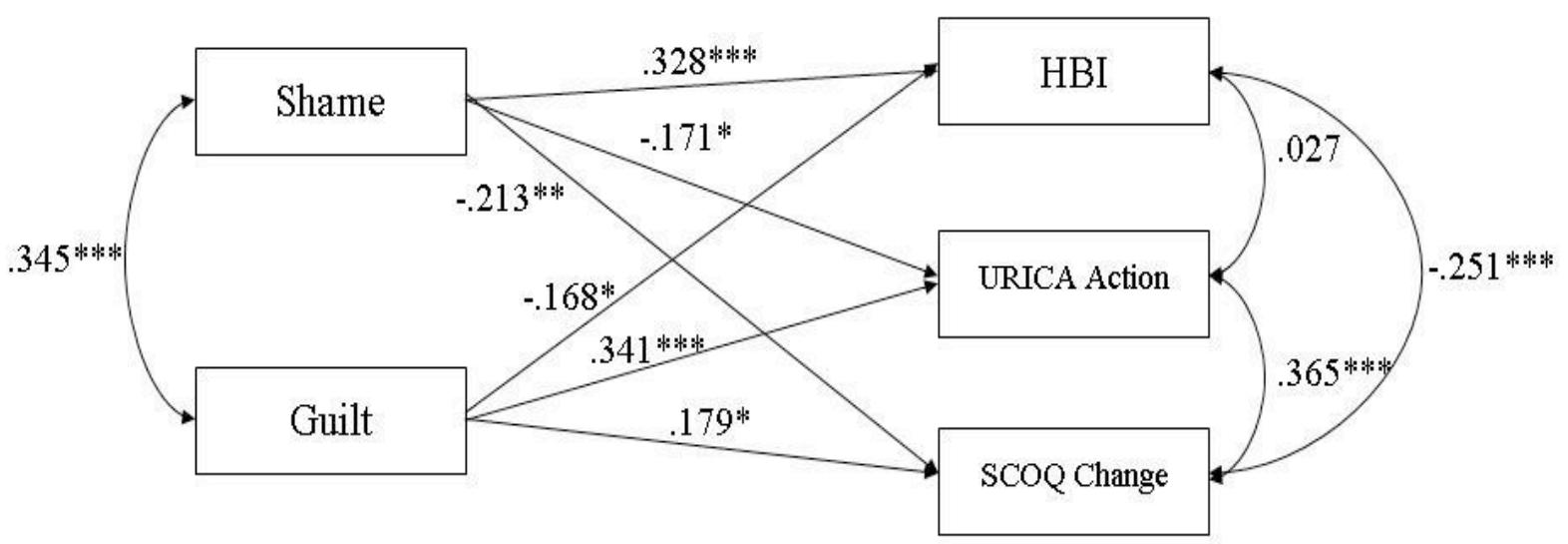

Figure 2. Hypothesized structural equation model of the effects of shame and guilt on hypersexual behavior (assessed by the HBI) and change (assessed by the URICA Action and the SCOQ Change). Coefficients on a double-arrow line are correlation coefficients; coefficients on a single-arrow line are standardized regression coefficients. ${ }^{*} p<.05, * *_{p}<.01, * * * p<.001$. 
Table 4

Path Coefficients from Hypothesized Model

\begin{tabular}{|c|c|c|c|c|}
\hline & Criterions & & & \\
\hline \multirow{3}{*}{ Predictors } & HBI & SCOQ Frequency & URICA Action & SCOQ Change \\
\hline & & & & \\
\hline & $\beta(S E)$ & $\beta(S E)$ & $\beta(S E)$ & $\beta(S E)$ \\
\hline TOSCA Shame & $.328 * * *(.08)$ & $.088(.09)$ & $-.171 *(.08)$ & $-.213 * *(.08)$ \\
\hline TOSCA Guilt & $-.168 *(.08)$ & $-.095(.09)$ & $.341 * * *(.08)$ & $.179 *(.08)$ \\
\hline
\end{tabular}

Many studies using path analysis seek to identify the best model to fit their data. The current exploratory study sought only to test the relationships between shame and guilt and the hypersexual and change variables. Because of this, a saturated model was tested, which included all possible model paths. Since all possible paths are tested, saturated models are reported as fitting the data perfectly, but model fit does not test correctness of the model.

Hypothesis 1. Hypothesis 1 had two parts: 1) TOSCA Shame scores would be more predictive of scores on the HBI than the TOSCA Guilt, and 2) Shame would have a positive relationship and guilt would have a negative relationship with hypersexuality. Both parts were supported by the model. The TOSCA Shame accounted for 33\% of the variance in HBI scores and was significant $(p<.001)$ while the TOSCA Guilt accounted for only $17 \%$ and was significant $(p<.05)$. Also, the TOSCA Shame had a positive relationship and guilt had a 
negative relationship with the HBI in both the correlation and regression analyses (as seen in Tables 2 and 3 ).

Hypothesis 2. It was also hypothesized that: 1) Scores on the TOSCA Guilt would have a positive relationship with the change variables (the URICA Action subscale and the SCOQ Change scale), and 2) The TOSCA Shame would have a negative relationship with the change variables. Both parts of hypothesis 2 were supported by the model. Guilt had a significant positive relationship while shame had a significant negative relationship with both change measures. TOSCA Guilt scores accounted for $34 \%$ of the variance of the URICA Action $(p<$ $.001)$ and $18 \%$ of the variance of the SCOQ Change $(p<.05)$. TOSCA Shame scores accounted for $17 \%(p<.05)$ and $21 \%(p<.01)$ of the variances of the URICA Action and the SCOQ Change variables, respectively.

According to the model, it was also hypothesized that Shame and Guilt would have a positive relationship with each other. We also theorized that the change variables (URICA Action and SCOQ Change) would have a negative relationship with the hypersexual variables (HBI and SCOQ Frequency). The data revealed that shame and guilt share a medium positive correlation, $r(146)=.35, p<.001$ while the SCOQ Change had a moderate negative correlation with the HBI, $r(147)=-.25, p<.001$, and a strong negative correlation with the SCOQ Frequency $r(157)=-.528, p<.001$. The URICA Action had a moderately negative correlation with the SCOQ Frequency $r(158)=-.203, p<.01$, and only a weak positive relationship with the HBI $r(147)=.027, n s$.

The effect sizes are presented in Table 2 using the $f^{2}$ statistic. Cohen's $f^{2}$ is an effect size indication when multiple regression is used. It is the ratio of $R^{2}$ divided by $1-R^{2}$. According to Cohen (1992), an $f^{2}$ value of .02 is considered a small effect size and an $f^{2}$ value of .15 is 
considered a medium effect size. Using this gauge, the SCOQ Change had a small effect size $\left(f^{2}\right.$ $=.05)$ while the HBI $\left(f^{2}=.11\right)$ and URICA Action $\left(f^{2}=.12\right)$ were between small and medium.

\section{Discussion}

Although previous literature has alluded to the differences between shame and guilt in hypersexual samples (Wilson, 2000; Adams \& Robinson, 2001; Reid, Harper \& Anderson, 2009), no study to date has empirically assessed how these two constructs are separately associated with behavior. Here we proposed that shame would be positively associated with higher scores on a hypersexuality measure while guilt would be positively associated with motivation to change hypersexual behavior. Results from this sample provide support for both of these hypotheses: the shame component from the TOSCA has a positive predictive relationship with hypersexual behavior reported on the HBI while the TOSCA guilt component has a significant, positive predictive relationship with self-reported change behaviors among people receiving therapy for pornography use. Conversely, guilt had a reliable negative predictive relationship with hypersexuality while shame had a reliable, negative predictive relationship with self-reported change behaviors. These latter findings are in line with research among other populations affected by compulsive and addictive behaviors, which likewise find stronger relationships between shame and unwanted behavior than relationships between guilt and unwanted behavior (Dearing, Stuewig \& Tangney, 2005; Sanftner, Barlow, Marschall \& Tangney, 1995).

This study has relevance for people seeking help for pornography use and therapists who work with them. The findings support the notion that shame needs to be addressed when treating patients that struggle with hypersexual behavior. In therapy, the practitioner can teach their client(s) the difference between shame and guilt and assess how their client reacts when tempted 
by or after using pornography. The therapist can teach their client how to recognize a shame reaction and techniques to reduce feelings of shame. Adams and Robinson (2001) offer five main suggestions to therapists as a means of reducing shame. First, the origin of the shame within the client and how it interacts with their behavior needs to be understood. Second, the therapist needs to clearly identify the differences between shame and guilt with the client. Third, the defenses used to avoid the painful feelings of shame need to be addressed. Fourth, as treatment moves forward, make use of shame reduction strategies (develop a therapeutic relationship, educate the client on the effects of shame, help clients realize the magnitude of their behavior and previous unsuccessful strategies to change, face the feelings behind the shame [inadequacy, worthlessness], and deal with the guilt). Finally, change the negative core beliefs that are the foundation of shame (Adams \& Robinson, 2001).

As discussed by Luyten, Fontain, and Corveleyn (2002), instead of assessing shame and guilt, the study might have only been assessing adaptive and maladaptive reactions to negative situations. Following their characterization, the tendency to react in a maladaptive way to negative situations has a positive predictive relationship with hypersexuality. This adds to the body of research demonstrating that hypersexual behavior is used as a maladaptive coping mechanism to deal with unwanted experiences or situations (Raymond, Coleman, \& Miner, 2003; Reid, 2010; Reid, Carpenter, Spackman, \& Willes, 2008).

As reported in Table 4, shame accounted for $33 \%$ of the predictive variance in HBI scores. In their study on shame and hypersexual behavior, Reid, Stein, and Carpenter (under review) reported that shame was not a significant predictor of hypersexuality on its own. Rather, neuroticism was a significant mediator: shame significantly predicted $37 \%$ of the variance in HBI scores only when neuroticism was included. This leaves open the possibility that adding 
measures of neuroticism may increase the associations such as we found. Reid, Stein, and Carpenter (under review) also found that, within neuroticism, an impulsivity subscale was the strongest predictor in their model. Thus, the painful effects of shame may be associated with neuroticism, which specifically is associated with impulsivity leading toward hypersexual behaviors. This fits the theory presented by Tice, Bratlsavsky, and Baumeister (2001), that when people are upset, they immediately engage in short-term "feel good" behaviors rather than sticking to long-term self-disciplinary goals. It is possible that the inclusion of impulsivity as a mediator between shame and hypersexuality could increase the predictive power of future hypothetical models.

\section{Motivation to Change}

Questions on the URICA Action assess a person's motivation to change their unwanted behavior, in this case their pornography use. The SCOQ Change adds an interesting twist because it goes a step further to measure the likelihood that someone is actually engaging in specific behaviors to limit their pornography use. For every one-unit increase in guilt, there is a $34 \%$ increase in recognizing that something is being done to change unwanted behavior (URICA Action), but only a $17 \%$ increase in actually doing something to change unwanted behavior (SCOQ Change). Even though guilt has been associated with a desire to change undesirable behavior, guilt alone may not be enough to motivate people to change.

The relationship between shame and motivation to change fits previous research which has found shame to be a barrier to help-seeking (Evans \& Delfabbro, 2005; Pulford, Bellringer, Abbott, Clarke, Hodkins, \& Williams, 2009). One of the components of shame is the fear of having unacceptable behavior exposed to the public eye (Lewis, 1971). Evans and Delfabbro (2005) found that among problematic gamblers, shame was higher among those who did not seek 
help for their problem compared to those that did. This could be due to the relationship between shame and externalization; the tendency for people to blame others or their circumstances for their problems when they are experiencing shame (Tangney, 2002). It is possible that people who are experiencing shame do not feel accountable for their problems and thus lack the motivation to change them.

\section{Measurement Confounds}

Although all of our hypothesized relationships were statistically significant and in the predicted direction, measures of effect size were only small or small-to-medium. One obvious concern is the lack of precision in many of the measures that were available, including the broad nature of the TOSCA Shame and Guilt measures, the general questions regarding hypersexual behavior on the HBI (without specific concerns focused just on pornography use) and the underdeveloped SCOQ, which has not been validated on large, external samples. Thus it may be that the development of more focused measures of shame and guilt, especially related to hypersexual behavior, may shed stronger light on their relation to engaging and potentially stopping such behavior. Of course it may also be that the proposed relationships between shame, guilt and hypersexual behavior are indeed small and/or clinically insignificant. Further research into measurement development is critical.

\section{Limitations and Future Research}

There were several limitations of the study. First, although not a completely homogenous group, the sample was narrow enough that the findings may not be generalizable to all groups of people struggling with hypersexual behaviors: the participants were predominantly religious, Caucasian, educated, heterosexual males. Due to the religiousness of the sample, it is likely that some of the sample have set a high standard for impermissible sexual activity which may not 
generalize to the population at large. There is a possibility that our sample struggled with additional hypersexual behaviors beyond pornography use, which we did not measure, including substance abuse, which is a common co-morbidity among hypersexual populations (Kafka \& Prentky, 1994). Since the data was collected online anonymously, there is a potential limitation that the participants could have taken the survey multiple times. This limitation was partially controlled by the Qualtrics ${ }^{\mathrm{TM}}$ software package, which did not allow the survey to be taken more than one time on the same computer (i.e., only one use per IP address). This was a crosssectional study, so it is possible that the data may support alternate directions in the path model (MacCallum, Wegener, Uchino, \& Fabrigar, 1993). This study also contains common limitations found in studies where self-report measures are used, such as the social desirability bias, where participants respond to questions in a way to project the best possible image of themselves (Kazdin, 2003). It is crucial to remember that these models are only correlational, and do not speak to any causal relationships. This study adds to the body of literature on hypersexual behaviors and suggests future areas of research. It would be interesting to see if the same results are found among a sample of people that meet the proposed DSM-V diagnosis for Hypersexual Disorder (Table 1). Empirical studies are needed regarding the effects of explicitly addressing shame during therapy with clients that struggle with hypersexual behaviors. This may be one key aspect in the development of an Empirically Supported Treatment for hypersexuality.

Shame, as used in this study, is a negative self-evaluative emotion directed towards the self as a whole. In order to improve treatment among people struggling with hypersexual behavior and other shame-prone populations, it would be advantageous to categorize underlying negative self-beliefs that lead to the feeling of shame. If a client is shameful because of feelings 
of worthlessness, the treatment approach will be much different than if the shame stemmed from a feeling of anger toward the self. Shame has been associated with a variety of constructs, including depression (Tangney, Wagner, \& Gramzow, 1992), anxiety (Grabhorn, Stenner, Stangier, \& Kaufhold, 2006), and anger (Tangney, Wagner, Fletcher, \& Gramzow, 1992). Do all of these tap into the same type of shame or can shame be further divided into subtypes? These questions need to be answered to advance the current understanding of shame.

\section{Conclusion}

As Hypersexual Disorder is being proposed for inclusion in the DSM-V (Kafka, 2010), more research is needed to understand this population of people that feel distressed and out of control from their sexual behavior. The current study adds support to other studies of shame among this population by distinguishing that it is shame and not guilt that is positively associated with hypersexual behavior. 


\section{References}

Adams, K. M., \& Robinson, D. W. (2001). Shame reduction, affect regulation, and sexualboundary development: Essential building blocks of sexual addiction treatment. Journal of Sexual Addiction and Compulsivity, 8(1), 23-44.

Alzate, H. (1978). Sexual behavior of Colombian female university students. Archives of Sexual Behavior, 7, 43-54.

American Psychiatric Association. (1980). Diagnostic and statistical manual of mental disorders (third ed., text revision). Washington, DC: Author.

American Psychiatric Association. (2000). Diagnostic and statistical manual of mental disorders (fourth ed., text revision). Washington, DC: Author.

Baldwin, K. M.; Baldwin, J. R.; Ewald, T. (2006). The Relationship among Shame, Guilt, and Self-Efficacy. American Journal of Psychotherapy, 60(1), 1-21.

Bancroft, J., \& Vukadinovic, Z. (2004). Sexual addiction, sexual compulsivity, sexual impulsivity, or what? Toward a theoretical model. Journal of Sex Research, 41, 225-234.

Barth, R. J., \& Kinder, B. N. (1987). The mislabeling of sexual impulsivity. Journal of Sex and Marital Therapy, 13(1), 15-23.

Bentler, P. M. (1980). Multivariate analysis with latent variables: Causal modeling. Annual Review of Psychology, 31, 419-456.

Bergner, R. M., Bridges, A. J. (2002). The significance of heavy pornography involvement for romantic partners: Research and clinical implications. Journal of Sex \& Marital Therapy, 28(3), 193-206. 
Black, D.W., Kehrberg, L. D., Flumerfelt, D.L., \& Schlosser, S. S. (1997). Characteristics of 36 subjects reporting compulsive sexual behavior. American Journal of Psychiatry, 154(2), 243-249.

Boyle, G. J. (1984). Reliability and validity of Izard's Differential Emotions Scale. Personality and Individual Differences, 5, 747-750.

Bridges, A. J., Bergner, R. M., Hesson-McInnis, M. (2003). Romantic partners' use of pornography: Its significance for women. Journal of Sex \& Marital Therapy, 29(1), 1-14.

Brown, J. (2004). Shame and domestic violence: Treatment perspectives for perpetrators from self psychology and affect theory. Sexual and Relationship Therapy, 19(1), 39-56.

Bybee, J., \& Quiles, Z. (1998). Guilt and mental health. Guilt and children (pp. 269-291). San Diego, CA US: Academic Press.

Carroll, J. S., Padilla-Walker, L. M., Nelson, L. J., Olson, C. D., Barry, C. M., \& Madsen, S. (2008). Generation XXX: Pornography acceptance and use among emerging adults. Journal of Adolescent Research, 23, 6-30.

Carnes, P. J. (1987). Sexual addiction: Implications for spiritual formation. Studies in Formative Spirituality, 8(2), 165-174.

Carnes, P. (2001). Cybersex, courtship, and escalating arousal: Factors in addictive sexual desire. Sexual Addiction \& Compulsivity, 8(1), 45-78.

Cohen, J. (1992). A power primer. Psychological Bulletin, 112(1), 155-159.

Coleman, E. (1991). Compulsive sexual behavior: New concepts and treatments. Journal of Psychology \& Human Sexuality, 4(2), 37-52.

Cooper, A. (1998). Sexuality and the Internet: Surfing into the New Millennium. Cyberpsychology \& Behavior, 1(2), 181-193. 
Cooper, A. (2002). Sex and the Internet: A guidebook for clinicians. New York: BrunnerRoutledge

Cooper, A. (2004). Online sexual activity in the new millennium. Contemporary Sexuality, 38(3), i-vii

Cooper, A., Delmonico, D. L., \& Burg, R. (2000). Cybersex users, abusers, and compulsives: New findings and implications. Sexual Addiction and Compulsivity, 7, 5-29.

Cooper, A., Putnam, D. E., Planchon, L. A., \& Boies, S. C. (1999). Online sexual compulsivity: Getting tangled in the net. Sexual Addiction \& Compulsivity, 6(2), 79-104.

Covert, M. V. (2004). Moderators of the effects of experimentally induced shame on indirect aggression (Doctoral dissertation). Dissertation Abstracts International: Section B: The Sciences and Engineering, Vol 65(2-B), 1062.

Daneback, K., Ross, M., \& Månsson, S. (2006). Characteristics and behaviors of sexual compulsives who use the internet for sexual purposes. Sexual Addiction \& Compulsivity, $13(1), 53-67$.

Davies, K. A. (1997). Voluntary exposure to pornography and men's attitudes toward feminism and rape. The Journal of Sex Research, 34(2), 131-137.

Dearing, R. L., Stuewig, J., Tangney, J. P. (2005). On the importance of distinguishing shame from guilt: Relations to problematic alcohol and drug use. Addictive Behaviors, 30, 13921404.

El-Jamil, F. M., (2003). Shame, guilt, and mental health: A study on the impact of cultural and religious orientation (Doctoral dissertation). Dissertation Abstracts International: Section B: The Sciences and Engineering, Vol 64(3-B),. pp. 1487. 
Earle, R. H., \& Crow, G. M. (1990) Sexual addiction: Understanding and treating the phenomenon. Contemporary Family Therapy: An International Journal, 12(2), 89-104.

Evans, L., \& Delfabbro, P. (2005). Motivators for change and barriers to help-seeking in australian problem gamblers. Journal of Gambling Studies, 21(2), 133-155.

Ferguson, T., \& Crowley, S. (1997). Measure for measure: A multitrait-multimethod analysis of guilt and shame. Journal of Personality Assessment, 69(2), 425-441.

Finlayson, A. J. R., Sealy, J., \& Martin, P. R. (2001); The differential diagnosis of problematic hypersexuality. Sexual Addiction \& Compulsivity, 8(3-4) 241-251.

Goodman, A. (1993). Diagnosis and treatment of sexual addiction. Journal of Sex and Marital Therapy, 19(3), 225-251.

Goodman, A. (2001). What's in a name? Terminology for designating a syndrome of driven sexual behavior. Sexual Addiction and Compulsivity, 8(3-4), 191-213.

Grabhorn, R., Stenner, H., Stangier, U., \& Kaufhold, J. (2006). Social anxiety in anorexia and bulemia nervosa: The mediating role of shame. Clinical Psychology and Psychotherapy, 13, 12-19.

Harder, D. W. (1992). Shame and guilt assessment, and relationships of shame- and guiltproneness to psychopathology. In: Tangney, J. P., \& Fischer, K. W. (Eds.), Selfconscious emotions: The psychology of shame, guilt, embarrassment, and pride (pp. 368392). New York, NY: Guilford Press.

Harder, D. W., \& Zalma, A. (1990). Two promising shame and guilt scales: A construct validity comparison. Journal of Personality Assessment, 55, 729-745.

Harder, D. W., Cutler, L., \& Rockart, L. (1992). Assessment of shame and guilt and their relationships to psychopathology. Journal of Personality Assessment, 59, 584-604. 
Hastings, A. S. (1998). Treating sexual shame: A new map for overcoming dysfunction, abuse, and addiction. Maryland: Jason Aronson.

Herman, J. L. (2007). Scattered shame states and their repair [PDF document]. Retrieved from http://www.scribd.com/doc/17538213/Shattered-ShameJudith-Lewis-Herman

Hill, P. C., Pargament, K. I., Swyers, J. P., Gorsuch, R. L., McCullough, M. E., Hood, R. W., \& Baumeister, R. F. (1998). Definitions of religion and spirituality. In D. B. Larson, J. P. Swyers, \& M. E. McCullough (Eds.), Scientific research on spirituality and health: A consensus report (pp. 14 -30). Baltimore: National Institute for Healthcare Research.

Izard, C. E. (1977). Human emotions. New York: Plenum Press.

Kafka, M. P. (1997). Hypersexual desire in males: An operational definition and clinical implications for males with paraphilias and paraphilia-related disorders. Archives of Sexual Behavior, 26(5), 505-526.

Kafka, M. P. (2010). Hypersexual Disorder: A proposed diagnosis for DSM-V. Archives of Sexual Behavior, 39(2), 377-400.

Kafka, M. P., \& Hennen, J. (1999). The paraphilia-related disorders: An empirical investigation of nonparaphilic hypersexuality disorders in outpatient males. Journal of Sex and Marital Therapy, 25(4), 305-319.

Kafka, M. P., \& Hennen, J. (2002). A DSM-IV Axis I Comorbidity Study of Males (n=120) With Paraphilias and Paraphilia-Related Disorders. Sexual Abuse: Journal of Research and Treatment, 14(4), 349-366.

Kafka, M. P., \& Prentky, R. (1994). Kafka, M., \& Prentky, R. (1994). Preliminary observations of DSM-III-R Axis I comorbidity in men with paraphilias and paraphilia-related disorders. Journal of Clinical Psychiatry, 55(11), 481-487. 
Kalichman, S. C, Johnson, R. R., Adair, V., Rompa, D., Multhauf, K., \& Kelly, J. A.(1994).

Sexual sensation seeking: Scaled development and predicting AIDS-risk behavior among homosexually active men. Journal of Personality Assessment, 62, 385-397.

Kazdin, A. (2003). Research design in clinical psychology (4th ed.). Needham Heights, MA US: Allyn \& Bacon.

Kline, R. (2005). Principles and practice of structural equation modeling (2nd ed.). New York, NY US: Guilford Press.

Krafft-Ebbing R. (1886). Psychopathia sexualis. Translated by Rebman F. J. New York, Physicians and Surgeons Book Co., 1927.

Lewis, H. B. (1971). Shame and guilt in neurosis. New York: International Universities Press. Lindsay-Hartz, J., de Rivera, J., \& Mascolo, M. (1995). Differentiating guilt and shame and their effects on motivation. Self-conscious emotions: The psychology of shame, guilt, embarrassment, and pride (pp. 274-300). New York, NY US: Guilford Press.

Lundy, J. P. (1994). Behavior patterns that comprise sexual addiction as identified by mental health professionals. Sexual Addiction and Compulsivity, 1(1) 46-56.

Luyten, P., Fontaine, J., \& Corveleyn, J. (2002). Does the Test of Self-Conscious Affect (TOSCA) measure maladaptive aspects of guilt and adaptive aspects of shame? An empirical investigation. Personality and Individual Differences, 33(8), 1373-1387.

MacCallum, R. C., Wegener, D. T., Uchino, B. N., \& Fabrigar, L. R. (1993). The problem of equivalent models in applications of covariance structure analysis. Psychological Bulletin, 114, 185-199.

Mahoney, E. R. (1980). Religiosity and sexual behavior among heterosexual college students. The Journal of Sex Research, 16, 97-113. 
McFarlane, M., Bull, S., \& Rietmeijer, C. A. (2000). Use of the Internet to solicit sex partners and related risk for STD among an inner city STD clinic population. Journal of the American Medical Association, 284(4), 443-446.

McConnaughy, E., Prochaska, J., \& Velicer, W. (1983). Stages of change in psychotherapy: Measurement and sample profiles. Psychotherapy: Theory, Research \& Practice, 20(3), 368-375.

Miller, W. R. (1999). Integrating spirituality into treatment: Resources for practitioners. Washington, DC: American Psychological Association.

Mingyi, Q., \& Jianli, Q. (2002). A comparative study on the difference between shame and guilt among Chinese college students. Acta Psychologica Sinica, 34(6), 626-633.

Murray-Swank, N. A., Pargament, K. I., Mahoney, A. (2005). At the Crossroads of Sexuality and Spirituality: The Sanctification of Sex by College Students. International Journal for the Psychology of Religion, 15(3), 199-219.

Muthén, L. K., \& Muthén, B. O. (2007). Mplus: Statistical analysis with latent variables: User's guide [Computer software manual]. Los Angeles: Muthén \& Muthén.

Myers, W. A. (1995). Addictive sexual behavior. American Journal of Psychotherapy, 49(4), 473-483.

Nelson, L. J., Padilla-Walker, L. M., Carroll, J. S. Prayer and pornography: Examining the correlates of pornography use for highly religious young men. Manuscript submitted for publication.

Nicholas, L., \& Durrheim, K. (1995). Religiosity, AIDS, and sexuality knowledge, attitudes, beliefs, and practices of black South African first-year university students. Psychological Reports, 77, pp. 1328-1330. 
O'Connor, L. E., Berry, J. W., Inaba, D., Weiss, J. (1994). Shame, guilt, and depression in men and women in recovery from addiction. Journal of Substance Abuse Treatment, 11(6), 503-510.

Oddone-Paolucci, E., Genuis, M., \& Violato, C. (2000). A meta-analysis of the published research on the effects of pornography. In C. Violato, E. Oddone-Paolucci, \& M. Genuis (Eds.), The changing family and child development (pp.48-59). Burlington, VT: Ashgate.

Orford, J. (1978). Hypersexuality: Implications for a theory of dependence. British Journal o Addiction, 73, 299-310.

Paul, C., Fitzjohn, J., Eberhart-Phillips, J., Herbison, P., \& Dickson, N. (2000). Sexual abstinence at age 21 in New Zealand: The importance of religion. Social Science and Medicine, 51, 1-10.

Potter-Efron, R. (1989). Shame, guilt and alcoholism: Treatment issues in clinical practice. New York, NY England: Haworth Press, Inc.

Prochaska, J. O., \& DiClemente, C. (1982). Transtheoretical therapy: Toward a more integrative model of change. Psychotherapy: Theory, Research, and Practice, 20, 161-173.

Pulford, J., Bellringer, M., Abbott, M., Clarke, D., Hodgins, D., \& Williams, J. (2009). Barriers to help-seeking for a gambling problem: The experiences of gamblers who have sought specialist assistance and the perceptions of those who have not. Journal of Gambling Studies, 25(1), 33-48.

Quadland, M. C. (1985). Compulsive sexual behavior: Definition of a problem and an approach to treatment. Journal of Sex and Marital Therapy, 11(2), 121-132.

Quiles, Z., \& Bybee, J. (1997). Chronic and predispositional guilt: Relations to mental health, prosocial behavior and religiosity. Journal of Personality Assessment, 69(1), 104-126. 
Raymond, N. C., Coleman, E., \& Miner, M. H. (2003). Psychiatric comorbidity and compulsive/impulsive traits in compulsive sexual behavior. Comprehensive Psychiatry 44(5), 370-380.

Reid, R. C. (2010). Differentiating emotions in a patient sample of hypersexual men. Journal of Social Work Practice in the Addictions, 10(2), 197-213.

Reid, R. C., Carpenter, B. N., Gilliland, R., \& Karim, R. (in press). Problems of self-concept in a patient sample of hypersexual men with attention-deficit disorder. Journal of Addiction Medicine.

Reid, R. C., Carpenter, B. N., Spackman, M., \& Willes, D. L. (2008). Alexithymia, emotional instability, and vulnerability to stress proneness in patients seeking help for hypersexual behavior. Journal of Sex and Marital Therapy, 34(2), 133-149.

Reid, R. C., \& Garos, S. (2007). A new measure of hypersexual behavior: Scale development and psychometrics. Paper presented at the Annual Convention of the American Psychological Association, San Francisco, California.

Reid, R. C., Harper, J. M., \& Anderson, E. H. (2008). Coping strategies used by hypersexual patients to defend against the painful effects of shame. Clinical Psychology \& Psychotherapy, 16(2), 125-138.

Reid, R. C., Stein, J. A., Carpenter, B. N. (under review). Understanding the roles of shame and neuroticism in a patient sample of hypersexual men.

Reid, R. C. \& Woolley, S. R. (2006). Using Emotionally Focused Therapy for Couples to resolve attachment ruptures created by hypersexual behavior. Journal of Sexual Addiction and Compulsivity, 13(2-3), 219-239. 
Richards, P. S., \& Bergin, A. E. (1997). A spiritual strategy for counseling and psychotherapy. Washington, DC: American Psychological Association.

Richards, P. S., \& Bergin, A. E. (Eds.). (2000). Handbook of psychotherapy and religious diversity. Washington, DC: American Psychological Association.

Rinehart, N. J., \& McCabe, M. P. (1997). Hypersexuality: Psychopathology or normal variant of sexuality? Sexual \& Marital Therapy, 12(1), 45-60.

Roane, D. M., Yu, M., Feinberg, T. E., \& Rogers, J. D. (2002). Hypersexuality after pallidal surgery in Parkinson disease. Neuropsychiatry, Neuropsychology, \& Behavioral Neurology,15(4), 247-251.

Roller, C. G. (2004). Sex addiction and women: A nursing issue. Journal of Addictions Nursing, $15(2) 53-61$.

Sanftner, J. L., Barlow, D. H., Marschall, D. E., Tangney, J. P. (1995). The relation of shame and gult to eating disorder symptomology. Journal of Social and Clinical Psychology, 14(4), 315-324.

Schmidt, C. W. (1992). Changes in terminology for sexual disorders in DSM-IV. Psychiatric Medicine, 10, 247-255.

Schwartz, M. F., \& Brasted, W. S.(1985). Sexual addiction: Self-hatred, guilt, and passive rage contribute to this deviant behavior. Medical Aspects of Human Sexuality, 19(10), 103107.

Shafranske, E. P. (Ed.). (1996). Religion and clinical practice of psychology. Washington, DC: American Psychological Association. 
Smith, R., Smith, M., Lambes, A., Dailey, W., \& Henry, N. (2004). The difference in sexual behavior between a Christian college and a state university. Indiana Wesleyan University Department of Psychology. Unpublished research manuscript.

Stein, D. J., Black, D. W., Shapira, N. A., \& Spitzer, R. L. (2001). Hypersexual disorder and preoccupation with Internet pornography. American Journal of Psychiatry, 158, 15901594.

Smith, D. E. (1994). Response to Jennifer Schneider. Sexual Addiction \& Compulsivity, 1(1), 45.

Spencer, J. A., \& Fremouw, W. J. (1979). Binge eating as a function of restraint and weight classification. Journal of Abnormal Psychology, 88, 262-267.

Stuewig, J., \& McCloskey, L. A. (2005). The relation of child maltreatment to shame and guilt among adolescents: Psychological routes to depression and delinquency. Child Maltreatment, 10(4), 324-336.

Tangney, J. P. (1991). Moral affect: The good, the bad, and the ugly. Journal of Personality and Social Psychology, 61, 598-607.

Tangney, J., Burggraf, S., \& Wagner, P. (1995). Shame-proneness, guilt-proneness, and psychological symptoms. Self-conscious emotions: The psychology of shame, guilt, embarrassment, and pride (pp. 343-367). New York, NY US: Guilford Press.

Tangney, J. P. \& Dearing, R. L. (2002). Shame and guilt. NY: Guilford Press.

Tangney, J. P., Miller, R. S., Flicker, L., \& Barlow, D. H. (1996). Are shame, guilt, and embarrassment distinct emotions? Journal of Personality and Social Psychology, 70(6), 1256-1269. 
Tangey, J. P., Wagner, P. E., Barlow, D. H., Marschall, E. E., \& Gramzow, R. (1996). The relation of shame and guilt to constructive vs. destructive responses to anger across the lifespan. Journal of Personality and Social Psychology, 70, 797-809.

Tangney, J. P., Wagner, P. E., Fletcher, C., \& Gramzow, R. (1992). Shamed into anger? The relation of shame and guilt to anger and self-reported aggression. Journal of Personality and Social Psychology, 62, 669-675.

Tangney, J. P., Wagner, P., Gramzow, R. (1992). Proneness to shame, proneness to guilt, and psychopathology. Journal of Abnormal Psychology, 101(3), 469-478.

Tice, D. M., Bratslavsky, E., Baumeister, R. F. (2001). Emotional distress regulation takes precedence over impulse control: If you feel bad, do it! Journal of Personality and Social Psychology, 80(1), 53-67.

Travin, S. (1995). Compulsive sexual behaviors. Psychiatric Clinics of North America, 18(1), 155-169.

Ullman, J. B. (1996). Structural equation modeling. In B. G. Tabachnick \& L. S. Fidell (Eds.), Using multivariate statistics (3rd ed.) (pp. 709-813). New York: HarperCollins College Publisher.

Washton, A., \& Boundy D. (2000). Willpower's not enough: Recovering from addictions of every kind. New York: HarperCollins.

Wilson, M. (2000) Creativity and shame reduction in sex addiction treatment. Sexual Addiction \& Compulsivity, 7(4), 229-248.

Wood, H. (2006). Compulsive use of Internet pornography. In J. Hiller, H. Wood, \& W. Bolton (Eds.), Sex, mind, and emotion: Innovation in psychological theory and practice (pp.6586). London, England: Karnac Books,. 
Worthington, E. L., Jr. (1988). Understanding the values of religious clients: A model and its application to counseling. Journal of Counseling Psychology, 35, 166-174.

Yelsma, P., Brown, N. M., Elison, J. (2002). Shame-focused coping styles and their associations with self-esteem. Psychological Reports, 90(3, Pt2), 1179-1189.

Young, K. S. (1998). Internet addiction: The emergence of a new clinical disorder. CyberPsychology \& Behavior, 1(3), 237-244.

Young, K. S. (2008). Internet Sex Addiction: Risk Factors, Stages of Development, and Treatment. American Behavioral Scientist, 52, 21-37.

Zillman, D., \& Bryant, J. (1982). Pornography, sexual callousness, and the trivialization of rape. Journal of Communication, 32(4), 10-21.

Zillman, D., \& Bryant, J. (1984). Effects of massive exposure to pornography. In N. Malamuth \& E. Donnerstein (Eds.), Pornography and sexual aggression (pp. 115-138). Orlando, FL: Academic.

Zillman, D., \& Bryant, J. (1988). Effects of prolonged consumption of pornography on family values. Journal of Family Issues, 9(4), 518-544.

Zillmann, D., Bryant, J. (1989).Pornography: Research advances and policy considerations. New Jersey: Lawrence Erlbaum. 


\section{Appendix}

\section{Sexual Concerns Outcome Questionnaire}

We appreciate your honest responses for the following questions. For this data to be helpful, we need as accurate of information as possible.

Some of the following questions ask about pornography use. We define pornography use as actively seeking out material that arouses sexual feelings, be it through (and not limited to) magazines, books, television, movies, music, the Internet, and the telephone. We do not include accidental or casual encounters with pornography to be considered pornography use.

Please answer the following in regards to frequency:

1) How often do you CURRENTLY look at pornographic material?

Never

— Rarely

A few times a Month

— Weekly

- A few times a week

Daily

- Multiple times per day

2) CURRENTLY, how long do you typically look at pornographic images on a day when you look at the material?

Never

5 minutes or less

Less than a half an hour

About an hour

- 1-2 hours

2-3 hours

_ More than 3 hours

3) Over the last six months, how long is the longest time period you have gone without masturbating?

One day

- 2-6 days

- One week

_ One to two weeks

- Two to four weeks

One month to three months

- 3-5 months 
6 months

4) How important is it to you to currently stop using pornography?

- Very important

Somewhat important

_ Neutral

Not very important

_ Not important at all

5) How important is it to you to currently stop masturbating?

Very important

_ Somewhat important

Neutral

Not very important

_ Not important at all

6) Since entering therapy, how often do you find that you fail to do what is expected of you (school work, job) due to looking at pornography?

Never

Less than monthly

Monthly

_ Weekly

_ Daily

7) How many years and/or months of your life have you actively sought out pornography (not including any time that you were able to abstain from it)? Years (please write)

Months (please write)

8) How many years and/or months of your life have you been going to therapy for pornographyrelated issues?

Years (please write)

_ Months (please write)

9) I use pornography-blocking software on my computer.

- Yes

_ No

10) I keep my computer in a public place.

Yes

No

Please use the following 5-point scale to rate how well the following statements describe you:

$$
\begin{gathered}
1--2--3-5-4 \\
\text { Never } \\
\text { Sometimes Always }
\end{gathered}
$$


11) _ I avoid the things that increase my desire to view pornography.

12) _ I avoid the things that increase my desire to masturbate.

13) _ I limit the amount of time I allow myself to go online.

14) _ Whenever I'm in a situation where I'm tempted to view pornography, I leave the situation.

15) _ Whenever I'm in a situation where I'm tempted to masturbate, I leave the situation.

16) _ I share my difficulties with someone who helps me with my problem.

17) _ When I make a mistake I give in and go overboard.

*SCOQ Change variable consisted of summing questions 9-16 and question 17 after reverse scoring. 